\title{
Mapeamento multitemporal e análise das formas de uso e ocupação do solo nos municípios de Baianópolis e Cristópolis, Bahia, Brasil
}

As imagens de satélite hoje disponibilizadas por órgãos de pesquisas são ferramentas tecnológicas de importância crucial para o estudo remoto de áreas que não podem ser percorridas facilmente, mas que precisam ser visualizadas, analisadas e estudadas. Assim, este trabalho objetivou avaliar o uso e ocupação do solo do Cerrado de dois municípios do Oeste da Bahia, Cristópolis e Baianópolis, região onde predomina a atividade de agricultura. Para o desenvolvimento desta pesquisa foram adquiridas imagens orbitais dos satélites Landsat 5, sensor TM (ThematicMapper) e Landsat 8, sensor OLI (Operational Terra Imager), orbita 219, e pontos 68 e 69, com resolução espacial de 30 metros, dos anos de 1989, 1994, 1999, 2004, 2009, 2014 e 2019. Essas imagens foram tratadas e, em seguida, submetidas à classificação supervisionada, onde foram identificadas seis classes de uso e ocupação do solo: área urbana, agricultura, queimadas, solo exposto, vegetação rasteira e vegetação densa. Essa classificação, demonstra que houve crescimento da agricultura ao longo dos últimos 30 anos, acompanhado pelo aumento das queimadas e de solo exposto, evidenciando que o crescimento econômico proporcionado pela atividade agro veio acompanhado de considerável degradação ambiental atingindo a fitofisionomia do Cerrado nativo dos municípios analisados, que são as vegetações rasteiras e densas. Conclui-se que o bioma requer atenção e o manejo sustentável deve ser buscado para a preservação da biodiversidade e minimização dos impactos sociais.

Palavras-chave: Sustentabilidade; Preservação; Ambiente; Sociedade.

\section{Multitemporal mapping and analysis of land use and occupation in the municipalities of Baianópolis and Cristópolis, Bahia, Brazil}

\begin{abstract}
The satellite images made available today by research agencies are technological tools of crucial importance for the remote study of areas that cannot be easily covered, but that need to be viewed, analyzed and studied. Thus, this study aimed to evaluate the use and occupation of the Cerrado soil in two municipalities in the West of Bahia, Cristópolis and Baianópolis, a region where agriculture is predominant. For the development of this research, orbital images of the Landsat 5 satellites, TM sensor (ThematicMapper) and Landsat 8, OLI sensor (Operational Terra Imager), orbita219, and points 68 and 69 , with spatial resolution of 30 meters, from the years 1989 were acquired, 1994, 1999, 2004, 2009, 2014 and 2019. These images were treated and then submitted to supervised classification, where 6 classes of land use and occupation were identified: urban area, agriculture, burning, exposed soil, undergrowth and dense vegetation. This classification shows that there was an increase in agriculture over the past 30 years, accompanied by an increase in fires and exposed soil, showing that the economic growth provided by agro-activity was accompanied by considerable environmental degradation, reaching the native Cerrado phytophysiognomy that are the low and dense vegetation in the cities analyzed. It is concluded that the biome requires attention and sustainable management must be sought in order to preserve biodiversity and minimize social impacts.
\end{abstract}

Keywords: Sustainability; Preservation; Environment; Society.

Topic: Desenvolvimento, Sustentabilidade e Meio Ambiente

Reviewed anonymously in the process of blind peer.
Received: 05/10/2020

Approved: 26/11/2020
Ranieldo Barreiras Barbosa Souza (iD

Universidade Federal do Oeste da Bahia, Brasil

http://lattes.cnpq.br/2995123274670779

http://orcid.org/0000-0001-6947-2872

ranieldosouza89@gmail.com

Francisco Rubens Feitosa Júnior (iD)

Universidade Federal do Oeste da Bahia, Brasil

http://lattes.cnpq.br/1603533849627421

http://orcid.org/0000-0001-7793-2138

rubenshaiek@gmail.com

Prudente Pereira de Almeida Neto (ic

Universidade Federal do Oeste da Bahia, Brasil

http://lattes.cnpq.br/4255612296660941

http://orcid.org/0000-0001-7480-0367

prudente.neto@ufob.edu.br

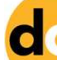

DOI: 10.6008/CBPC2179-6858.2020.006.0037
Paulo Roberto Baqueiro Brandão (iD

Universidade Federal do Oeste da Bahia, Brasil

http://lattes.cnpq.br/4084176901171467

http://orcid.org/0000-0002-8342-9130

paulo.baqueiro@ufob.edu.br

Referencing this:

SOUZA, R. B. B.; FEITOSA JÚNIOR, F. R.; ALMEIDA NETO, P. P.; BRANDÃO, P. R. B.. Mapeamento multitemporal e análise das formas de uso e ocupação do solo nos municípios de Baianópolis e Cristópolis, Bahia, Brasil. Revista Ibero Americana de Ciências Ambientais, v.11, n.6, p.451-471, 2020. DOI: http://doi.org/10.6008/CBPC2179$\underline{6858.2020 .006 .0037}$ 


\section{INTRODUÇÃO}

O Cerrado brasileiro é o segundo maior bioma da América do Sul, ocupando aproximadamente 2 milhões de $\mathrm{km}^{2}$. No entanto, nos últimos anos, cerca de metade do seu território foi transformado em áreas cultivadas e de pastagens, duas vezes a conversão observada na Amazônia nos últimos cinco anos, com a maior parte da conversão da vegetação nativa tendendo a ocorrer em áreas com vegetação densa e terrenos planos (MMA, 2009; ALENCAR et al., 2020)

O Cerrado apresenta elevada riqueza de espécies vegetais, totalizando 11.627 espécies nativas, porém, dessas, 132 espécies da flora estão ameaçadas de extinção. Embora detentora de grande biodiversidade de formações florestais, como mata ciliar, mata de galeria, mata seca, cerradão, savanas e outras características do bioma, ressalta-se o crescimento de áreas cultivadas e de pastagens anualmente (MMA, 2009; VACCHIANO et al., 2019; GONÇALVES et al., 2019)

Com o intuito de oficializar a região como área de propagação do agronegócio no país, o Estado brasileiro, por meio da Embrapa (Empresa Brasileira de Pesquisa Agropecuária) fez de grande parte desse território uma fronteira agrícola, chamada de MATOPIBA (cujo termo resulta do acrônimo formado pelas siglas dos estados do Maranhão, Tocantins, Piauí e Bahia). Essa região caracteriza-se, sobretudo, por um interno processo de reestruturação territorial produtiva gerada pela produção de grãos e especulação fundiária (SOUZA et al., 2019).

A partir de uma perspectiva geográfica, é possível perceber a formação de regiões especializadas na produção agrícola voltada para o mercado externo, como ocorre no já mencionado MATOPIBA, que, dentre as diversas consequência desse processo, pode-se destacar a conversão da vegetação natural em pastagens e terras agrícolas, fomentando, desta forma, a simplificação da biodiversidade (ANACHE et al., 2018; HUGHES, 2017; LAPOLA et al., 2014).

No Brasil, a expansão recente das áreas agricultáveis do Cerrado fomentou a migração de agricultores das regiões Sul e Sudeste para as regiões Norte e Nordeste do país, principalmente para o complexo MATOPIBA, considerado como a nova fronteira agrícola brasileira (ZANIN et al., 2017).

No Oeste da Bahia, mais precisamente, apresenta solos ácidos e índice pluviométrico moderado, com uma distribuição irregular de chuvas, o que compromete o estabelecimento de muitas culturas agrícolas (OLIVEIRA et al., 2015). Entretanto, durante a década de 1970, fatores como baixo preço das terras, topografia plana e incentivo de políticas públicas, impulsionaram o desenvolvimento da agricultura modernizada na região (BUAINAIN et al., 2016).

Nessa região, os processos de uso e ocupação do solo têm produzido grandes pressões sobre os sistemas naturais, em decorrência da interação entre sociedade e natureza (SANTOS, 2011; CHAICHI et al., 2018), resultado de interações físicas, biológicas, políticas, econômicas e sociais, fragmentadas ou conectadas para diferentes usos da terra (GOERL et al., 2011).

Além disso, a urbanização, por exemplo, é responsável pela degradação progressiva do meio ambiente e, nas últimas décadas, é notada a convenção constante de cobertura florestal contínua em 
paisagem fragmentada (SOULSBURY et al., 2015; GOUDIE, 2018). De igual modo, a ocorrência de distúrbios, como o fogo e outras formas de degradação antropogênica, apresenta-se como desafios para a existência da biodiversidade no Cerrado (JACON et al., 2017).

Nos últimos anos, há uma demanda crescente por novas tecnologias ecológicas e as séries temporais de uso e cobertura do solo, vem sendo mais utilizadas, em decorrência da possibilidade de identificar e acompanhar as mudanças nos padrões de uso do solo e vegetação, gerando estimativas de desmatamento (SANTOS, 2011).

O conhecimento do comportamento temporal fornece alternativas de prevenção de inundações, melhor uso de recursos naturais e serviços ecossistêmicos para sortimento de cidades, agricultura, atividade industrial e outros, principalmente porque as respostas espectrais das savanas mudam drasticamente da estação chuvosa para a seca (JACON et al., 2017).

Assim, atualmente, faltam informações sobre a importância de vários fatores ambientais que afetam o Cerrado nesta região, principalmente para as áreas protegidas. Neste sentido, o trabalho ora exposto tem o objetivo de apresentar mapas multitemporais de áreas do Cerrado localizadas em dois municípios do Oeste da Bahia, utilizando uma combinação das séries Landsat para delimitação de áreas nativas e antropizadas nos últimos anos, analisando, ainda, as modificações ocorridas nos anos de 1989, 1994, 1999, 2004, 2009, 2014 e 2019, para responder às seguintes perguntas: (a) Como as atividades antrópicas modificaram a paisagem natural? (b) Como a recorrência de queimadas é espacialmente alastrada?

A análise de imagens de sensoriamento remoto é uma excelente ferramenta para detectar focos de incêndio, avaliar o desmatamento, prever desastres ambientais, monitorar a expansão urbana e sua relação com o meio físico (RIDD et al., 1998; GRANEMANN et al., 2009). Desta forma, presente trabalho busca contribuir para uma melhor compreensão da evolução do uso e ocupação do solo em dois municípios da região Oeste da Bahia e identificar, principalmente, possíveis implicações da ocupação antrópica ao longo das últimas décadas.

\section{MATERIAIS E MÉTODOS}

\section{Áreas de estudo}

O estudo foi realizado no Território de Identidade da Bacia do Rio Grande, no estado da Bahia (MDA, 2015), mais precisamente nos municípios de Baianópolis e Cristópolis (Figura 1). O primeiro possui uma extensão territorial de $3.428,7 \mathrm{Km}^{2}$, com latitude de $26^{\circ} 56^{\prime} 07^{\prime \prime}$ e longitude: 44ㅇ 32' 05" W, clima subúmido seco, com variações de temperaturas entre $18,8^{\circ} \mathrm{C}$ e $25,4^{\circ} \mathrm{C}$ e precipitações pluviométricas que variam de $800 \mathrm{~mm}$ a $1.100 \mathrm{~mm}$, por ano. Em parte do município, existe uma transitoriedade para o clima semiárido, com variações médias de temperatura de $20,7^{\circ} \mathrm{C}$ a $26,8^{\circ} \mathrm{C}$ e precipitações anuais que variam de $500 \mathrm{~mm}$ a $800 \mathrm{~mm}$ (SEI, 2011).

Quanto a parte da área de estudo localizada no município de Baianópolis, situa-se no distrito de Várzea, Comunidade de Brejinho. Em um levantamento feito pela CBPM-BA (2007), a fitofisionomia 
vegetativa se apresenta entre arbórea do tipo Chapadão e gramíneo-lenhosa que, por estar inserida no bioma Cerrado, é visível a sua distribuição em árvores de pequeno porte e florestas de galerias distribuídas em partes.

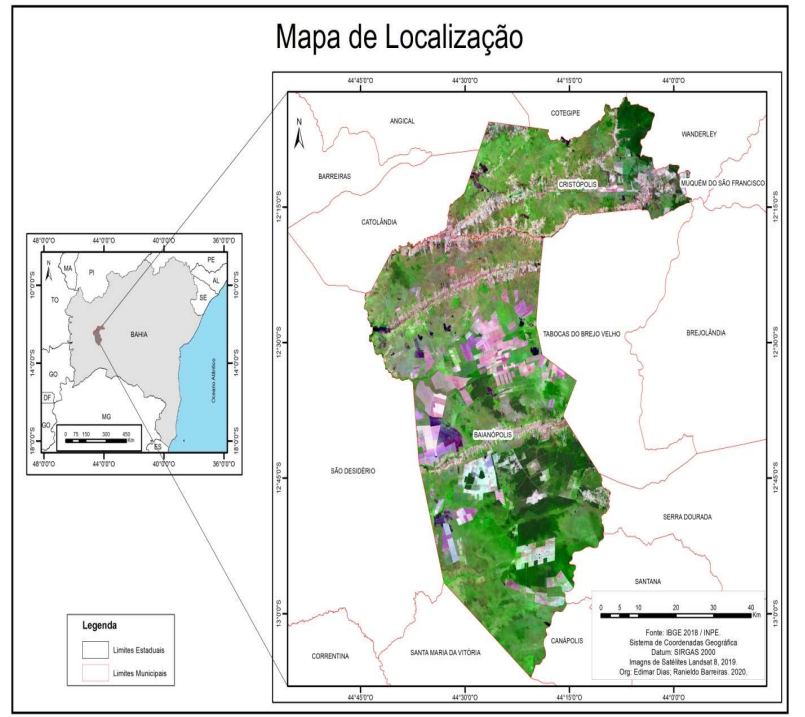

Figura 1: Localização dos municípios de Baianópolis e Cristópolis. Fonte: INPE (2019).

A segunda área de estudo é na zona rural do município de Cristópolis, mais precisamente na Fazenda Alemão, cujas coordenadas geográficas identificadas são latitude -12ำ14’01'” e longitude - 44ํ5⒖ O clima definido é subúmido a seco e úmido, com temperatura média de $18,8^{\circ} \mathrm{C}$ a $25,4^{\circ} \mathrm{X}$. De acordo com a SEI (2016), a fisionomia vegetacional predominante é o Cerrado, apresentando uma fisionomia arbórea aberto, sem floresta de galeria.

Uma vez definida a área de estudo, os procedimentos adotados para o desenvolvimento do trabalho proposto consistiram em dois momentos: obtenção dos dados orbitais e processamento das imagens.

\section{Obtenção dos dados orbitais}

Tabela 1: Dados de aquisição das imagens.

\begin{tabular}{|c|c|c|c|c|c|c|c|}
\hline \multicolumn{4}{|c|}{ Baianópolis } & \multicolumn{4}{|c|}{ Cristópolis } \\
\hline Ano & Satélite / Sensor & Órbita_Ponto & Data de Passagem & Ano & Satélite / Sensor & Órbita_Ponto & Data de Passagem \\
\hline 1989 & \multirow{5}{*}{ Landsat - 5/TM } & \multirow{7}{*}{ 219_069 } & 01/10/1989 & 1989 & \multirow{5}{*}{ Landsat - 5 / TM } & \multirow{7}{*}{ 219_068 } & 01/10/1989 \\
\hline 1994 & & & 31/10/1994 & 1994 & & & $31 / 10 / 1994$ \\
\hline 1999 & & & 27/09/1999 & 1999 & & & 27/09/1999 \\
\hline 2004 & & & 24/09/2004 & 2004 & & & 24/09/2004 \\
\hline 2009 & & & 28/08/2009 & 2009 & & & 28/08/2009 \\
\hline 2014 & \multirow{2}{*}{ Landsat - 8 / OLI } & & $06 / 10 / 2014$ & 2014 & \multirow{2}{*}{ Landsat - 8 / OLI } & & $06 / 10 / 2014$ \\
\hline 2019 & & & $20 / 10 / 2019$ & 2019 & & & $20 / 10 / 2019$ \\
\hline
\end{tabular}

Fonte: INPE (2019).

Para a realização desta pesquisa, foram utilizadas imagens orbitais dos satélites Landsat 5 , sensor TM (Thematic Mapper) e Landsat 8, sensor OLI (Operational Terra Imager), orbita219, e pontos 68 e 69, com resolução espacial de 30 metros, com lapso temporal de cinco em cinco anos, entre 1989 e 2019. As imagens selecionadas foram dos meses de agosto e outubro (Tabela 1), inseridos no período seco, para uma melhor classificação, e sempre nos mesmos dias para cada ano utilizado. Buscou-se selecionar as cenas com menor percentual de cobertura de nuvens. Esses dados foram obtidos gratuitamente, por meio dos sites eletrônicos do Serviço Geológico dos Estados Unidos (USGS), e do Instituto Nacional de Pesquisas Espaciais (INPE). 
Os dados referentes à delimitação dos municípios da área de estudo, na forma vetorial, do tipo shapefile, foram obtidos a partir do site do Instituto Brasileiro de Geografia e Estatística (IBGE).

\section{Processamento das imagens}

Após a seleção e coleta das imagens, as mesmas foram processadas em ambiente de Sistema de Informação Geográfica (SIG), nos softwares QGIS versão 2.18.25 (software livre) e ArcGis versão 10.4.1 do Laboratório de Geoprocessamento (LABGEO), pertencente à Universidade Federal do Oeste da Bahia (UFOB).

Nas imagens Landsat 8 - OLI dos anos de 2014 e 2019 foram realizadas composições coloridas e posteriormente reprojetadas para o Hemisfério Sul, com o sistema de coordenadas UTM (Universal Transversa de Mercator), Datum Horizontal SIRGAS 2000 Zona 23 Sul.

Nas imagens Landsat 5 - TM referentes aos anos de 1989, 1994, 1999, 2004 e 2009 foram realizadas composições coloridas e, posteriormente, a correção geométrica polinomial de primeira ordem, com seis pontos de controle, tendo como referência imagens Landsat 8 - OLI reprojetadas para o Hemisfério Sul.

Após isso, as imagens dos respectivos anos foram recortadas para os limites dos municípios e, em seguida, realizada a classificação supervisionada, onde foi possível identificar, por meio da fotointerpretação das imagens, elementos como tonalidade/cor, textura (rugosidade), forma/padrão, permitindo, assim, definirmos quatro classes de uso e ocupação do solo1: Solo Exposto; Queimadas; Vegetação Rasteira e Vegetação Densa. Após a definição das classes de uso, foi possível quantificar as áreas pertencentes a cada classe, como será apresentado nos resultados.

\section{RESULTADOS E DISCUSSÃO}

\section{Evolução multitemporal do uso e ocupação da terra em Baianópolis e Cristópolis}

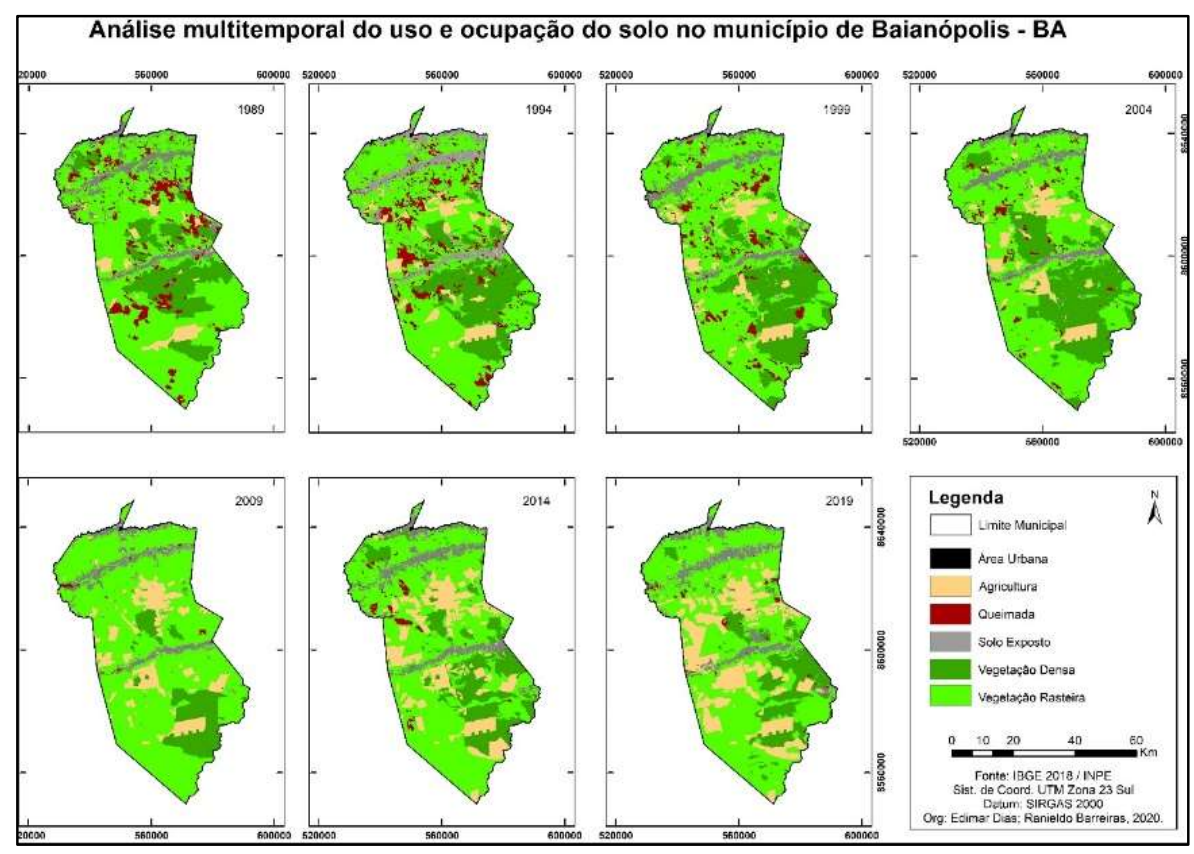

Figure 2: Ocupação territorial do município de Baianópolis. Fonte: INPE (2019).

\footnotetext{
${ }^{1}$ Para este trabalho, a classe urbana não foi abordada devido à resolução das imagens capturadas, neste caso, de 30 metros. Com isso, não foi possível determinar, com a aplicação da metodologia descrita, o crescimento das áreas urbanas no período examinado, mantendo constante os seus valores de áreas de ocupação para Baianópolis e Cristópolis.
} 
A seguir, é apresentada a área, em quilômetros quadrados, com ênfase no uso e ocupação do território municipal de Baianópolis a partir do emprego de dados em Shapefile dos anos de 1989, 1994, 1999, 2004, 2009, 2014 e 2019, tendo como tratamento a Área Urbana, Agricultura, Queimadas, Solo Exposto, Vegetação Rasteira e Vegetação Densa. A Figura 2 é a representação do Município de Baianópolis em três décadas, com imagem gerada através do Landsat.

Os dados referentes aos valores de cada classe em $\mathrm{Km}^{2}$, para cada período, estão apresentados na tabela 2 de forma cronológica.

Tabela 2: Uso e ocupação do solo em Baianópolis - BA em 30 anos.

\begin{tabular}{|c|c|c|c|c|c|c|c|}
\hline \multicolumn{8}{|c|}{ Uso e Ocupação em Área Km² } \\
\hline Classes & 1989 & 1994 & 1999 & 2004 & 2009 & 2014 & 2019 \\
\hline Área urbana & 1,11 & 1,11 & 1,11 & 1,11 & 1,11 & 1,11 & 1,11 \\
\hline Agricultura & 145,80 & 244,90 & 268,20 & 299,77 & 384,52 & 557,92 & 702,58 \\
\hline Queimadas & 301,90 & 315,87 & 198,63 & 96,65 & 12,37 & 50,98 & 27,80 \\
\hline Solo exposto & 292,30 & 324,65 & 275,19 & 244,31 & 235,50 & 271,85 & 288,94 \\
\hline Vegetação rasteira & 1988,70 & 1781,60 & 1863,44 & 1805,87 & 2333,16 & 1861,56 & 1870,60 \\
\hline vegetação densa & 588,90 & 650,67 & 712,00 & 870,56 & 352,12 & 575,34 & 428,00 \\
\hline
\end{tabular}

Fonte: INPE (2019).

\section{Agricultura}

Conforme apontamentos do IBGE sobre a área plantada na Região Oeste da Bahia, onde o município de Baianópolis está inserido, no período de 1990 a 2020, os principais produtos agrícolas da área são a soja, algodão e milho, cujas produções são voltadas, majoritariamente, para atendimento de outros mercados que não o regional.

De 1989 a 1994 o crescimento no desmatamento para agricultura foi de 2,38\%. Em 1994 a 1999 houve uma leve queda para 0,7\%, voltando a aumentar para 1\% entre 1999 a 2004 e seguindo trajetória ascendente entre 2004 e 2009, com 2,5\%, para alcançar o pico de desmatamento no período de 2009 a 2014, com 6\%, e, finalizando, entre 2014 e 2019, com leve queda de 5\%. Esse processo totalizou aproximadamente 22\% de área desmatada para a agricultura nos últimos trinta anos.

Segundo Guimarães et al. (2018), a partir do ano 2000, foi verificado em Baianópolis, uma ocupação intensiva nas áreas de interflúvio, onde as condições ambientais são propícias para a agricultura mecanizada. Os resultados apresentados pelos autores demonstraram que as APP do município apresentavam, em 1988, $80,4 \%$ de sua área total preservada, diminuindo, em 2008, para 77,4\%, em função do avanço da agropecuária e da vegetação alterada, compreendida como área que sofreu alteração na vegetação natural e/ou foi desmatada, ainda que não necessariamente utilizada para fins de produção agrícola.

A utilização do solo para fins de agricultura cresceu ao longo dos anos de forma considerável. Entre o final da década de 1980 e 2004, esse crescimento era gradativo, ano a ano, o que é justificado pelo início da reestruturação do setor agrícola no município, com decréscimo dos investimentos do estado passaram a diminuir com o intuito de atrair investimentos privados para o setor e, assim, buscar desenvolver a exportação de grãos (BARBOSA et al., 2008), em um momento histórico de estabilização da moeda e baixo valor de aquisição de terras no Oeste da Bahia, o que repercutiu no considerável aumento de investidores 
na região (HELFAND et al., 2003).

Houve também interferência direta do governo da Bahia na região por meio da implantação de programas de incentivos para alavancar o crescimento da atividade agrícola de alto rendimento, como, por exemplo, o AGROINVEST (Programa de Modernização da Agricultura Baiana) e o PROBAHIA (Programa de Promoção do Desenvolvimento da Bahia) (SEAGRI, 2003). Em 2019, as terras utilizadas para essa finalidade já correspondiam a quatro vezes mais, comparando-se com 1989. Isso diz respeito a aproximadamente $22 \%$ do território municipal de Baianópolis.

Ao longo dos anos, houve um aumento continuado da área cultivada, passando de $5 \%$ do território em 1989 , para $22 \%$ em 2019 , representando uma redução de cerca de $1 / 5$ da cobertura vegetal do município., ou seja, uma taxa de quase 1\% de desmatamento por ano. Ademais, no período de 1988 a 1992, a área de vegetação natural reduziu o equivalente a $8,2 \%$.

No entanto, segundo Guimarães et al. (2018), no contexto do Oeste da Bahia, o município de Baianópolis ainda possui elevado percentual de vegetação natural, notadamente se comparado a outros municípios com elevado desempenho agrícola, como Barreiras e São Desiderio, onde a taxa de desmatamento é bastante superior.

\section{Queimadas}

O acúmulo de biomassa seca, resultantes do período de escassez de chuva, que é característica do bioma Cerrado, torna-se um combustível eficaz ao mínimo contato com o fogo ou até mesmo quedas de raios. Coutinho (2008) afirma que, em algumas situações, o fogo é incontrolável pelo homem e, com isso, a fauna foge do habitat natural ou sucumbe, enquanto a flora, apesar do seu poder de regeneração, tende a perder sua densidade, se submetida frequentemente a altas temperaturas, como as queimadas e incêndios. Ou seja, a ameaça para a biodiversidade do Cerrado é certa.

Conforme estudo sobre os biomas brasileiros realizado por Jesus et al. (2020), o cerrado teve maior área queimada em 2007, apresentando maior quantidade de focos de fogo ao longo de toda a série temporal analisada. Ainda segundo os autores, a maior incidência de focos no bioma se dá entre os meses de junho e outubro, o que corrobora com os estudos de Araújo (2015) e Alvarado et al. (2017), que confirmam ser o período mencionado como o de pico de queimadas na região.

No entanto, em se tratando do município de Baianópolis, quanto à classe representada pelas queimadas, ficou patente que houve uma queda significativa de ocorrências, tendo alcançado $91 \%$ de redução no número de pontos de calor no período entre 1989 e 2019.

Até o final da década de 1980, o fogo já havia atingido cerca de $9 \%$ do total do território municipal de Baianópolis. Entre 1989 e 1994, esse número subiu para 10\%, tendo caído para 6\% no quinquênio seguinte e, de novo, entre 1999 a 2004, chegando a 3\%, e, daí, para 0,4\% entre 2004 e 2009. Contudo, nos cinco anos seguintes, houve novo crescimento $(1,5 \%)$ e finalizando o período com nova redução, atingindo $0,85 \%$ da área em análise.

Vale mencionar que, no município, persiste a prática da preparação das áreas de cultivo por meio do 
uso da queimada para manejo de solo, sendo a forma mais fácil de 'limpar o terreno' para usos diversos. Isso, decerto, colabora para a manutenção de focos ainda identificados em tempos hodiernos.

Por outro lado, é provável também que, nos anos em que as incidências de pontos de calor foram detectadas em grandes quantidades, como no interstício entre 1989 e 1999, isso tenha ocorrido pelo fato do satélite ter registrado esses focos de incêndio um pouco depois da região ter sido atingida por queimadas, haja visto que as imagens de satélites foram adquiridas em períodos de estiagem no Oeste da Bahia.

\section{Solo exposto}

O solo exposto representa um tipo de perturbação no ambiente pela retirada da camada protetora da superfície da terra, tornando-a incapaz de se regenerar naturalmente, o que implica na necessidade de realizar intervenções para a sua recuperação (CORRÊA et al., 1998).

No caso de Baianópolis, as oscilações detectadas na interpretação de imagens podem estar relacionadas ao fato de que é necessário remover terra, em sua superfície, para que haja uma preparação para o cultivo em geral sem a intervenção da vegetação nativa. Isso explica a constante diminuição da área, conforme se verá a seguir, representando, assim, uma regeneração da vegetação, o que não quer dizer, necessariamente, que seja de vegetação nativa. Neste caso, os locais podem ter sofrido intervenções de interesses econômicos.

Para a classificação solo exposto, houve uma oscilação no seu aumento e na sua diminuição. Até o ano de 1989, o território possuía 8,8\% de solo exposto. De 1989 a 1994, foi a 9,8\%. De 1994 a 1999 alcançou 8,3\%, seguido de 7,4\% entre 1999 a 2004, 7,1\% entre 2004 e 2009. De 2009 a 2014, chegou a 8,17\%, finalizando em 2014 e 2019 com 8,7\%. Um total de 10\% do território de vegetação nativa, transformada em solo exposto. Uma taxa de $0,5 \%$ de aumento ao ano.

Nota-se, pelo cruzamento de dados, que, naqueles períodos em que houve maior crescimento da agricultura, ocorreu, também, diminuição da área de solo exposto. Em estudo realizado por Guimaraes et al. (2018) afirma-se que, ao longo de vinte anos analisados, o município perdeu cerca de $20 \%$ de sua vegetação natural para a agropecuária e a vegetação alterada. Em 1988, cerca de $40 \%$ de todo uso no município (Agropecuária, Vegetação Alterada, Área Urbana/Vila/Loteamento) encontrava-se nas Chapadas Intermediárias (o uso total no município era de $385 \mathrm{~km}^{2}$ e nas chapadas era de $170 \mathrm{~km}^{2}$ ), entretanto, em 2008 , esse percentual alcança de $68 \%$ de todo uso no município (o uso total do município era de $909 \mathrm{~km}^{2}$ e nas chapadas de $610 \mathrm{~km}^{2}$ ).

Além disso, cabe ressaltar que os autores acima afirmam que, continuando neste ritmo de crescimento de $30 \%$ de transformação de áreas de vegetação natural a cada quatro anos, as Chapadas Intermediárias, em 2028, terão toda sua área ocupada.

\section{Vegetação rasteira}

Para a classe de vegetação rasteira, representada, nesta pesquisa, pelas gramíneas típicas do tipo de Cerrado que ocorre no município de Baianópolis, mas podendo ser representada, também, pela parte de 
vegetação destinada à atividade pastoril presente na região. Essa diferenciação não foi captada pelas imagens adquiridas devido à resolução espacial.

Até 1989 , a vegetação rasteira presente no munícipio correspondia a $60 \%$ ou quase $2 / 3$ de todo o território. De 1989 a 1994, essa proporção caiu para 53\%, sendo esse o período de maior diminuição dessa área vegetativa. Correlacionando esses dados com as classes citadas anteriormente, foi nesse período que houve o maior número de pontos de calor e, também, a maior porção de solo exposto, correspondendo, ainda, à fase inicial de introdução da atividade agrícola moderna no Oeste da Bahia, conforme aponta Coutinho (2008).

De 1994 a 1999 houve um leve aumento nessa vegetação, chegando a 56\%. Esse período foi acompanhado de queda nos focos de calor e no solo exposto, evidenciando, assim, que algumas áreas sofreram intervenções para fins de agropecuária. No período de 1999 a 2004, observou-se queda de 2\%, chegando a $54 \%$.

A cobertura rasteira, teve sua maior alta no período de 2004 a 2009, alcançando 70,3\% do território estudado, com estabilização nos interstícios seguintes (2009 a 2014 e 2014 a 2019) em 56\%. Essa estabilização é resultado da ocorrência de áreas já finalizadas, ou seja, de uso permanente do plantio para fins econômico. As áreas hoje plantadas, sofreram preparações ao longo da primeira década, se estabilizando na seguinte. Não há registros de grandes propriedades destinadas a agricultura implantadas recentemente no munícipio.

\section{Vegetação densa}

Em estudo realizado na região Oeste da Bahia por meio de sensoriamento remoto, Borges et al. (2014) identificaram 5,1\% como pertencente à classe de Cerrado ralo na área na região, afirmando também que o Cerrado típico é a fitofisionomia predominante, mas é, proporcionalmente, a vegetação mais suprimida, tendo em vista as características das áreas onde ocorrem - topografia plana e solos bem desenvolvidos proporcionam o avanço da agricultura mecanizada em larga escala. A série de EVI utilizada pelos autores para esta classe apresentou baixo desvio padrão. Por outro lado, os resultados encontrados para classe Cerrado denso constitui-se em manchas mais esparsas e localiza principalmente nas proximidades das bordas dos chapadões e representa 9,6\% da área de estudo. Esta fitofisionomia é caracterizada por arbustos e árvores, porém, com densidade maior do que a encontrada no Cerrado típico.

Para a classe de vegetação densa, aqui considerada como vegetação de vereda, que é um subsistema do Cerrado presente no território de Baianópolis, constatada visualmente em visitas técnicas, além das florestas plantadas, também presentes no território e cuja verificação da sua ocorrência pôde ser feita in loco. Possuem os seus fragmentos espalhados, em menor quantidade, na porção norte do município, mas também na porção central e, em maior abundância na parte sul e sudeste do território, mais distantes, portanto, da área urbana.

Em 1989, essa área densa ocupava 18\% do território, havendo aumento significativo dessa vegetação nos anos seguintes, sendo 20\% entre 1989 e 1994, 21\% entre os anos 1994 e 1999 e 25\% para o período de 
1999 e 2004. A pouca interferência do homem no meio natural, pode ter contribuído para o aumento dessa vegetação. É nesse período, que a agricultura está acertando passos rumo à expansão, o que explica a conservação dessas áreas no município, ocorrendo sucessivas quedas de área ocupada nos interstícios seguintes.

Entre os anos de 2004 e 2009 as áreas de vegetação densa reduzem para 10\%, perdendo, em uma década, metade de sua cobertura inicial. É o início da expansão agrícola no município, deixando clara a interferência dessa reestruturação produtiva na natureza. Entre 2009 e 2014 alcançou quase a totalidade da área inicial, chegando a 19\% e voltou a cair no período de 2014 até o final de 2019, alcançando 13\%.

\section{Evolução multitemporal do uso e ocupação da terra em Crisópolis}

A seguir, é apresentada a área, em quilômetros quadrados, com ênfase no uso e ocupação do território municipal de Cristópolis a partir do emprego de dados em Shapefile dos anos de 1989, 1994, 1999, 2004, 2009, 2014 e 2019, tendo como classes a Área Urbana, Agricultura, Queimadas, Solo Exposto, Vegetação Rasteira e Vegetação Densa. A Figura 3 é a representação do Município de Cristópolis em três décadas, com imagem gerada através do Landsat.

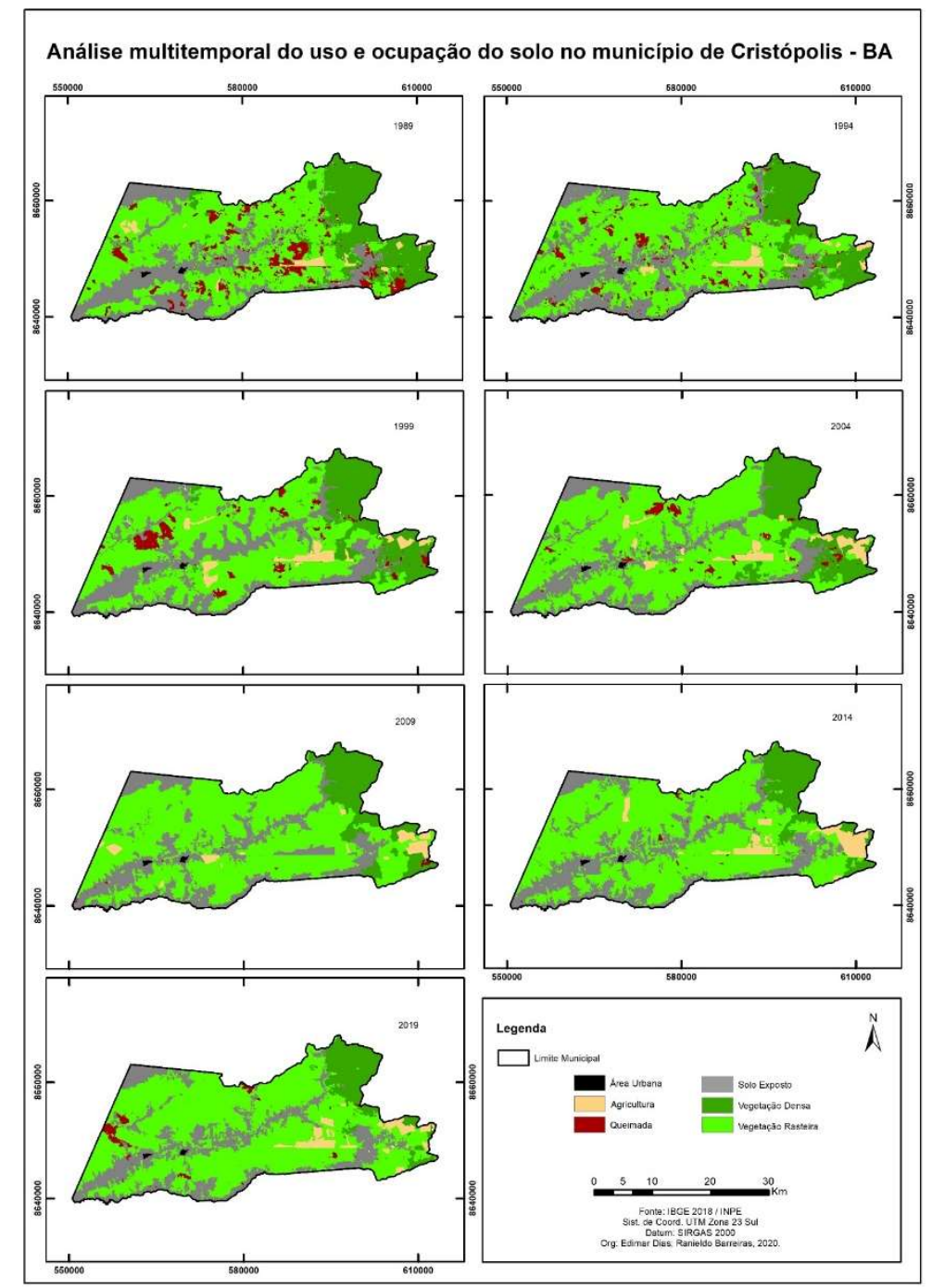

Figura 3: Ocupação territorial do município de Cristópolis. Fonte: INPE (2019). 
Na Tabela 3 é apresentada cronologicamente em intervalos de 5 anos o Uso e ocupação no município de Cristópolis de 1989 até 2019.

Tabela 3: Uso e ocupação do solo - Cristópolis - BA.

\begin{tabular}{|c|c|c|c|c|c|c|c|}
\hline \multicolumn{8}{|c|}{ Uso e Ocupação em Área Km² } \\
\hline Classes & 1989 & 1994 & 1999 & 2004 & 2009 & 2014 & 2019 \\
\hline Área urbana & 2,18 & 2,18 & 2,18 & 2,18 & 2,18 & 2,18 & 2,18 \\
\hline Agricultura & 17,85 & 22,27 & 35,43 & 39,05 & 37,50 & 46,49 & 35,00 \\
\hline Queimadas & 77,12 & 44,22 & 37,57 & 20,36 & 2,93 & 3,51 & 14,97 \\
\hline Solo exposto & 245,74 & 268,40 & 266,99 & 220,64 & 226,20 & 253,22 & 232,31 \\
\hline Vegetação rasteira & 514,59 & 562,28 & 545,45 & 603,78 & 658,82 & 641,69 & 671,86 \\
\hline vegetação densa & 194,62 & 152,90 & 164,53 & 166,14 & 124,54 & 105,02 & 95,74 \\
\hline
\end{tabular}

Fonte: INPE (2019).

\section{Agricultura}

Nota-se que as áreas destinadas à agricultura estão localizadas majoritariamente na porção leste do território, afastado do centro urbano, com propriedades que chegam a 18 mil hectares localizados, em sua maioria, às margens da BR 242, sentido capital do estado baiano. As ditas propriedades estão assentadas em áreas de topografia plana e levemente onduladas.

Ao longo dos anos, houve um aumento da área cultivada, passando de 1,71\% do território, em 1989, para 5\% no quinquênio de maior desmatamento para finalidade agrícola, correspondente ao período de 2009 a 2014. Isso representa uma baixa de quase $7 \%$ da cobertura vegetal do município, com uma taxa de perda de $0,35 \%$ ao ano.

De 1989 a 1994, o desmatamento para abertura de espaços para a agricultura cresceu 1,71\%. No interstício entre 1994 e 1999 houve um leve incremento de 0,4\%, ganhando ascendência para 3\% entre 1999 a 2004. Continuou a subir entre 2004 e 2009 com 3,71\%. De 2009 a 2014, foi a 5,47\%, finalizando o período de 2014 a 2019 com 7\% de área desmatada para a agricultura nas últimas três décadas.

O crescimento da área agrícola verificado no final da década de 1980 foi fruto do início da modernização agroexportadora na região Oeste da Bahia, a partir de 1985. Esse resultado é também retratado na pesquisa de Sano et al. (2011), que ressalta o uso e ocupação do solo no estado da Bahia por meio de imagens de satélites, percebendo o aumento significativa da cultura agrícola na região. Ainda segundo Sano et al. (2011), antes de 1985, a ocupação do solo nessa região era simples e de modo controlado. Isso explica o fato de, em 1989, a quantidade desmatada para a agricultura ser ainda baixa se comparada com os anos posteriores.

Observa-se ainda que o crescimento da área de agricultura, foi acompanhado pela diminuição da vegetação rasteira e densa. O mesmo resultado foi encontrado por Flores et al. (2012), ao analisarem imagens de satélite de Barreiras, município vizinho a Cristópolis. Fica patente, pois, que o crescimento da agricultura no Cerrado da região se deu por meio da diminuição da vegetação natural.

In loco, foi observado pelos pesquisadores, que as grandes propriedades no município pertencem a proprietários imigrantes, que chegaram à região devido as condições de crescimento no setor. Vale salientar, de passagem, que a pavimentação asfáltica da BR 242, que abriu o acesso da capital ao interior, teve sua 
contribuição nesse processo.

No período entre 2004 e 2009 houve uma diminuição de áreas com atividades agrícolas. Essa redução também foi observada por Menke et al. (2009), em sua pesquisa desenvolvida no município de Luís Eduardo Magalhães, também no Oeste da Bahia. Ele atribui isso ao fato do surgimento, desenvolvimento e implantação de novas tecnologias, destinadas ao aproveitamento do espaço de plantio. Essas novidades tecnológicas, aos poucos foram sendo implantadas em toda a região oeste.

O pico do desmatamento para plantio foi no período compreendido entre 2009 e 2014, momento em que ocorreram maiores incentivos dos setores públicos e privados, onde os bancos passavam a financiar o agricultor resultando assim no aumento das exportações de grãos. Para Garcia (2019), o auge da participação brasileira no comércio internacional ocorreu em 2011, com as exportações totais próximas de $1,5 \%$ da mundial.

De modo adicional, em sua análise sobre as exportações brasileiras de 1998 a 2018, Garcia (Idem) afirma que o Brasil passou a exportar menos após 2012. Esse fator pode ter interferido diretamente na produção agrícola do município de Cristópolis, entre 2014 e 2019 da área plantada. Gonçalves (2011) atribui essa queda ao declínio econômico sofrido pelo país, resultando em mudanças no comércio de exportação brasileira.

\section{Queimadas}

Para a classe representada pelas queimadas, houve uma queda significativa ao longo dos anos, tendo alcançado 80,5\% de redução no número de pontos de calor no período entre 1989 e 2019, segundo as imagens analisadas.

Até 1989, o fogo já havia engolido cerca de 7,5\% do total do território de Cristópolis. Entre 1989 e 1994, esse número foi reduzido para 4,2\%. Entre 1994 e 1999, houve uma nova queda nesse número, chegando a 3,5\%. De 1999 a 2004, decresceu a 1,9\%, despencando consideravelmente entre 2004 e 2009 e no quinquênio seguinte, com 0,27 e 0,33, respectivamente, e finalizando o interstício de 2014 a 2019 com leve alta, indo a $1,4 \%$.

Até 1989, o município sofreu mais com as queimadas. Não há nenhum registro de grandes atividades de plantio que possam explicar a amplitude desses focos de queimada na localidade. Com isso, a causa que mais se aproxima para o fato são os incêndios naturais, seguido de queimadas acidentais. Ademais, é possível perceber, na imagem do mesmo ano, que esses pontos possuem espaçamentos entre si, conseguindo atingir todas as regiões do território, desde mais próxima à área urbana, até pontos mais distantes, nos extremos do município.

Apesar de, então, a população ser, em sua maioria, rural, resultando em ocupação de grandes áreas de pastagens para criação de animais para subsistência, o que poderia levar a uma explicação apressada sobre o fenômeno das queimadas, deve-se levar em consideração uma característica do próprio bioma: para Cochrane (2009), em períodos de estiagens prolongadas, devido ao ressecado extremo da vegetação do Cerrado, uma simples queimada pode ter consequências desastrosas, visto que a seca torna a flora um 
combustível natural.

Em um estudo sobre focos de incêndio na Serra da Canastra ao longo da década de 1980, Lemes et al. (2014) relataram que $60 \%$ da área de estudo haviam sido consumidas pelo fogo. Os autores atribuem o fato à forte pressão causada pela seca, onde até mesmo um raio leve poderia ter causado tamanho desastre. Ademais, a análise de Mesquita et al. (2011) para o caso da Chapada Diamantina, também referente à década de 1980 , identificou uma proporção de $6,8 \%$ de área afetada por fogo, um valor que se aproxima do encontrado nesta pesquisa, para o caso do município de Cristópolis.

Na década seguinte e até 2004, ainda havia presença de focos de fogo, mas em valores menores que o demonstrado para 1989. Nesse interstício, as causas estavam atreladas aos incêndios típicos do período de estiagem, comum no bioma, conforme já sinalizado, mas também em função de uma demanda crescente por áreas garantidoras de um processo de expansão agrícola, conforme relatado por Barbosa et al. (2008).

Após esse período, os focos de calor diminuíram entre 2004 e 2019. Atualmente, na região, os focos de calor ocorrem como consequência dos períodos de seca, estando relacionados, em sua maioria, portanto, a causas naturais ou provocadas acidentalmente (INPE, 2019).

\section{Solo exposto}

O solo exposto é um tipo de degradação ambiental resultante, principalmente, da ação humana. Essa prática geralmente é marcada pela retirada da vegetação e da parte do solo que contém os nutrientes que proporcionariam uma possibilidade de regeneração, fato já constatado por Gomide et al. (2011) e Silva (2019).

Para a classe identificada como solo exposto, houve um aumento de área na década de 1990, em comparação com os anos anteriores. Até 1989, o território municipal de Cristópolis possuía $23,5 \%$ de solo exposto. Contudo, nos dois interstícios seguintes, ou seja, de 1989 a 1994 e entre 1994 e 1998, esse percentual se manteve em 25,5\%. No período compreendido entre 1999 a 2004, houve uma queda na área identificada com solo exposto, alcançando os $21 \%$, seguido de leve aumento entre 2004 a 2009, indo a 22,5\%. No quinquênio entre 2004 a 2014, houve um novo, indo a 24\%, e voltou a cair novamente entre 2014 e 2019, finalizando o período desta análise em $22 \%$, o que representa uma taxa de crescimento de 1,2\% ao ano.

No início do período em exame, essas áreas de solos expostos estavam concentradas, majoritariamente, nas porções oeste e central do munícipio, com tendência de prolongamento por uma faixa lindeira à BR 242 e no entorno da área urbana. Por outro lado, vale mencionar que algumas áreas identificadas como solo exposto na imagem de 1989 foram transformadas em áreas de agricultura no início da década seguinte, permitindo inferir que esses fragmentos possivelmente possuíam cobertura vegetativa, tendo sofrido manipulação posterior, para fins econômicos. Essa informação corrobora com as abordagens de Menke et al. (2009) e Flores et al. (2012) sobre o início da expansão agrícola na região.

Nota-se que, à medida em que houve a diminuição de solos exposto nos interstícios de 2009 a 2014 e 2014 a 2019, houve também um crescimento da agricultura, revelando relação de causa e efeito entre os dois fatores e, portanto, uma interação entre ambas as classes. 


\section{Vegetação rasteira}

$\mathrm{Na}$ análise das imagens de Cristópolis, a classe de vegetação rasteira apresentou, ao longo de todo o período analisado, um acréscimo de $23 \%$, correspondendo a uma elevação de $0,8 \%$ ao ano.

Até o ano de 1989, a vegetação rasteira presente no munícipio correspondia a 50\% de todo o território, considerando ser a vegetação de gramíneas bastante típica nessa região do bioma Cerrado. Ao longo do quinquênio de 1989 a 1994, houve um ligeiro crescimento, para 53,5\%, que não se repetiu no interstício seguinte, já que essa presença dessa vegetação atingiu 51,8\%. No entanto, entre 1999 a 2004 observou-se significativo aumento, alcançando os $57,3 \%$ de vegetação rasteira, com nova alta indo a $62,5 \%$, nos cinco anos seguintes (2004 a 2009). Cresceu novamente entre 2009 a 2014, com 64\%, de vegetação rasteira.

Com esta análise, observou-se que, a partir da primeira década do século XXI, a vegetação rasteira aumentou proporcionalmente ao crescimento da agricultura no município. Em contrapartida, houve uma diminuição de pontos de calor, à medida em que a vegetação rasteira se alongava. Esse padrão de relação já foi citado em outros estudos, como naqueles realizados por Menke et al. (2009) e Flores et al. (2012), nas respectivas análises sobre os municípios de Luís Eduardo Magalhães e Barreiras, também localizados no Oeste da Bahia. Esse crescimento vegetativo quando da captura das imagens, ou seja, em períodos de extrema estiagem, evidencia que tais áreas sofreram intervenções para fins de desenvolvimento das práticas agropecuárias.

Vale salientar também que, de 1994 a 1999, época de maior presença de pontos de calor, de igual modo, foi um período em que se observou áreas de vegetação rasteira convertidas em agricultura, o que converge com o que Coutinho (2008) aponta como o início da expansão agrícola no Oeste da Bahia.

\section{Vegetação densa}

Para a vegetação densa, aqui considerada como vegetação de vereda, que é um subsistema do Cerrado, mata de galeria e florestas plantadas, presentes no território de Cristópolis e cuja constatação foi feita, além das imagens, por meio de visitas técnicas. Essas formações estão concentradas, quase que em sua totalidade, nas porções leste e sudeste do território, com pequenos fragmentos espalhados também pela porção norte do município. Contudo, importa salientar que esses fragmentos foram subtraídos completamente após a década de 1990, sendo sua concentração atual nas poções leste e sudeste, distantes da área urbana.

Em 1989, essa vegetação densa ocupava $18 \%$ do território, diminuindo ao longo dos últimos trinta anos de forma considerável, sendo 14,5\% entre 1989 e 1994, 15,5\% de 1994 a 1999 e 15,7\% para o quinquênio 1999 a 2004. Nesse período, a agricultura ainda estava no processo inicial de sua a expansão, o que explica certa manutenção dessas áreas do município, algo que não se manteve ao longo das décadas seguintes.

Entre os anos de 2004 e 2009, a vegetação densa teve a sua área diminuída para 11,8\% do território 
municipal de Cristópolis, perdendo, em uma década, pouco mais de $1 / 3$ de sua cobertura inicial. Esse interstício corresponde a um momento de expansão agrícola na região, deixando clara a interferência do homem na natureza. O quinquênio seguinte - de 2009 a 2014 - foi de nova queda, dessa vez atingindo apenas 9,8\%, enquanto 2014 e 2019, acabou por alcançar a sua menor ocorrência, ou seja 9\% do município, valor que representa a exata metade da área existente em 1989, ano de início da temporalidade desta pesquisa.

Foi observado que os fragmentos de vegetação densa que desapareceram ao longo desses anos foram convertidos em vegetação rasteira. Essa conversão permite inferir que a sua causa tenha sido a perda de acúmulo de água nas veredas. Tal fato foi descrito por moradores locais em conversas informais realizadas quando das visitas técnicas. Essa parte densa do Cerrado, é composta por espécies arbóreas com capacidade de cobertura de até $70 \%$, o que explica a sua densidade, diferenciando-se dos outros estratos mais rasteiros detectados pela captura feita via satélite (ALCÂNTARA NETO et al., 2011).

Para Siqueira (2016), em seu estudo sobre espécies na Alta Bacia do Rio Araguaia, a perda desse tipo de fitofisionomia do Cerrado, ou seja, o denso, pode acarretar vários outros tipos de prejuízos ambientais, dentre os quais, a perda do habitat de fauna e flora locais, alterando totalmente os aspectos evolutivos das espécies. Ademais, prejuízos ambientais de tal magnitude impactam decisivamente as espécies do Cerrado em Cristópolis, com consideráveis implicações socioambientais nas formas de reprodução social das comunidades rurais desse município.

Vale mencionar que, entre 2014 e 2019, houve perda total da vegetação densa na parte sul do território municipal, área que teve parte convertida em vegetação rasteira e parte em área de agricultura. De acordo com observação in loco, essa vegetação rasteira ou gramínea não corresponde apenas à vegetação nativa, mas áreas plantadas com vegetação de pasto para alimento de animais.

O crescimento da agricultura ao longo dos anos resultou em perda desse tipo de vegetação, mostrando, assim, uma relação direta e inversamente proporcional dessa classe, cujos resultados similares também estão presentes nas pesquisas de Menke et al. (2009) e Flores et al. (2012).

\section{Uso e ocupação do solo em Baianópolis e Crisópolis: uma comparação}

Apesar de Baianópolis ser três vezes maior que Cristópolis, levando em consideração a extensão territorial, algumas correlações do uso e ocupação relativos ao lapso temporal de trinta anos desta pesquisa podem ser feitas. De início, é possível afirmar que os dois municípios apresentaram evolução da agricultura ao longo dos anos abordados (Gráfico 1). Isso permite inferir que ambas as áreas estudadas apresentaram desmatamento considerável para o plantio, em uma relação três vezes maior para o caso de Baianópolis, em comparação com Cristópolis.

Segundo a Secretaria de Agricultura do Estado da Bahia - SEAGRI (2017), no município de Baianópolis há intensa produção de soja e algodão. Junto com outros municípios do Oeste da Bahia, em 2017, esta unidade político-administrativa contribuiu para a produção de aproximadamente 1,2 milhões de toneladas de algodão, o que posicionou a Bahia como o segundo maior produtor dessa commodity no Brasil. A SEAGRI atribui essa produtividade às condições de clima e topografia da região, bem como ao baixo custo de 
produção por hectare.

Em Cristópolis, por sua vez, o Instituto de Pesquisas Econômicas Aplicadas - IPEA (2011), registrou produção de cana de açúcar equivalente em 1,01\% do território, milho em 0,5\%, além de arroz e soja. Além disso, conforme confirmado pela Embrapa (2013), o município é responsável por grande produção de alho que, até 2002, era de cerca de 700 toneladas ao ano, passando para 2000 toneladas em 2013 e com estimativa de atingir o dobro até 2023. Vale frisar que, embora esteja sob administração familiar, mais de 300 hectares de área do Cerrado da Bahia estão destinados à produção de alho.

Observa-se que Baianópolis apresentou crescimento de áreas convertidas em plantio em todos os anos estudados, enquanto Cristópolis apresentou queda em 2009 e 2019, fato possivelmente ocasionado pelo período de preparação para replantio. Não há dados publicados sobre redução de área de plantio em nenhum dos dois municípios.

As queimadas, sempre presentes na região Oeste da Bahia em períodos de seca, mostra-se em declínio na última década, se comparado com o período inicial desta investigação, observados os municípios em estudo. Essa redução nos números de focos de incêndios chega a aproximadamente 90\% para Baianópolis, onde, inicialmente, 301,9 ha de Cerrado haviam sido consumidos pelo fogo, ao passo que, em 2019, o território sob efeito de queimadas e incêndios foi reduzido para 27,8 ha.

Em Cristópolis, houve uma dimensão inicial de 77,12 ha atingidas pelo fogo enquanto, em 2019, a área atingida declinou para 14,97 há, correspondendo a uma redução de aproximadamente $82 \%$ de focos de calor detectados nas imagens de satélite analisadas. No Gráfico 2, é possível visualizar essa informação de forma detalhada entre os municípios.

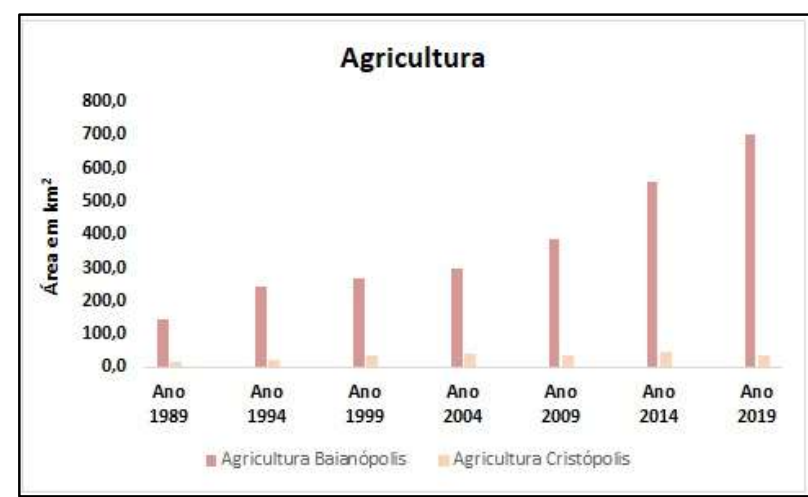

Gráfico 1: Baianópolis e Cristópolis na Bahia em 30 anos. Fonte: INPE (2019).

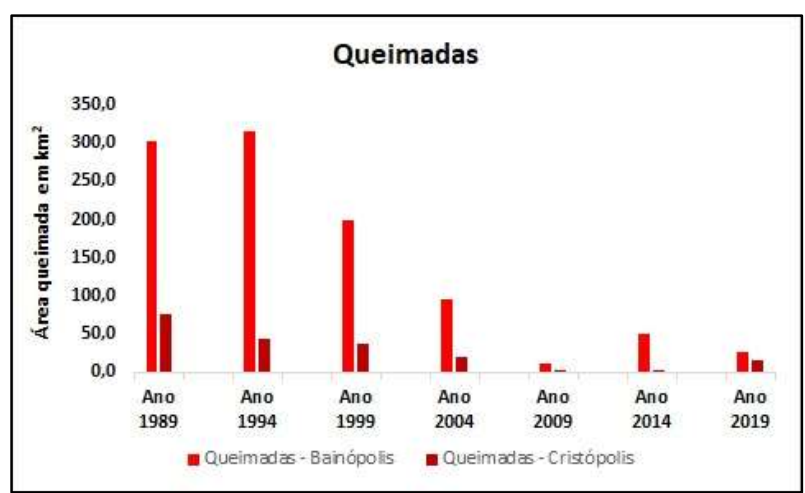

Gráfico 2: Baianópolis e Cristópolis na Bahia em 30 anos. Fonte: INPE (2019).

Esses números, embora sejam positivos, pois resultam de menores áreas sob efeito de queimadas e incêndios, ainda são preocupantes, quando se trata de mensurações acerca da preservação da rica biodiversidade do Cerrado. Dados de queimadas do Instituto Nacional de Pesquisas Espaciais - INPE (2019), apontam que, entre as décadas de 1990 e 2000, o estado da Bahia apresentou seu pico de queimadas. Isso devido ao início da expansão das fronteiras do agronegócio, resultante da preparação de terra para o plantio.

O INPE aponta ainda o Cerrado brasileiro como sendo o segundo maior bioma atingido por queimadas, alcançando quase 138 mil focos de incêndios em 2007 e quase 133 mil focos em 2010. Esse ápice, 
está exatamente presente no contexto de criação do MATOPIBA² (SILVA et al., 2018). Ao todo, são aproximadamente 73 milhões de hectares destinados ao projeto de expansão agrícola mencionado e os territórios de Baianópolis e Cristópolis estão inseridos nessa região de cultivo (MIRANDA, 2015).

Por outro lado, as áreas com exposição do solo são o retrato da retirada da cobertura vegetacional e é resultado da ação das práticas citadas anteriormente, ou seja, desmatamento para agricultura e queimadas. No território de Baianópolis há uma queda nos anos de 2009 e 2014, voltando a assumir característica de ampliação em 2019, com resultados praticamente iguais àqueles verificados em 1989. No caso de Cristópolis, também houve uma redução de área degradada por exposição do solo nos anos de 2004 e 2009, mas finalizando o período deste estudo com alta considerável. Embora nos anos de 2004 e 2009 tenha havido quedas nas áreas de solos expostos, pode-se afirmar que, em trinta anos, não houve diminuição significativa.

Fausto et al. (2016), em uma análise por imagens do Cerrado do município de Barra do Bugres, no sul do Mato Grosso, observou que uma grande parte do território estudado era destinada à agricultura e mais de $23 \%$ eram compostos por solo exposto. Além da perda da biodiversidade e dos impactos sociais, o autor ainda observou o aumento da temperatura na área do solo exposto em relação àquelas com cobertura vegetal. Assim, a ocupação da terra para agricultura e a retirada da vegetação natural são tipos de degradação ambiental, também presentes nos dois municípios retratados nesse trabalho.

As quantidades comparativas de áreas com solos expostos em Cristópolis e Baianópolis, podem ser visualizadas no Gráfico 3.

O Gráfico 4 mostra a variação da vegetação rasteira nos municípios de Baianópolis e Cristópolis. O ano de 2019 foi finalizado com diferenças percentuais mínimas com relação aos dados das últimas três décadas, sendo que para Cristópolis houve um aumento de 30\% com relação a 1989 e Baianópolis uma redução de $6 \%$ desse tipo de vegetação.

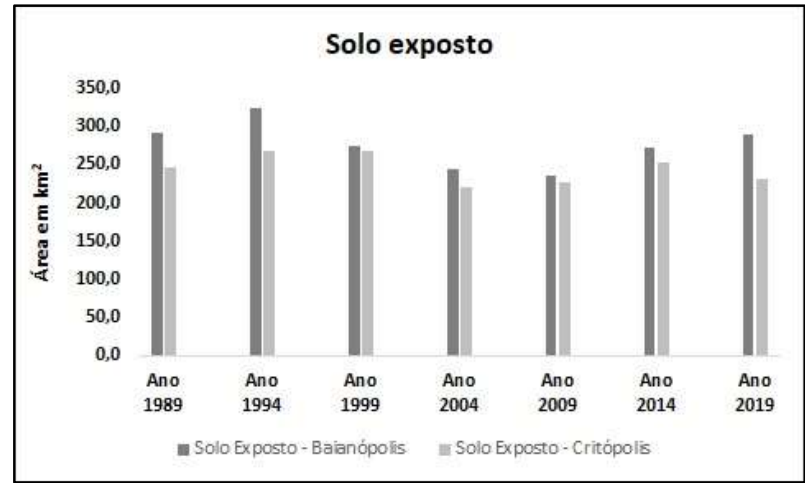

Gráfico 3: Baianópolis e Cristópolis na Bahia em 30 anos. Fonte: INPE (2019).

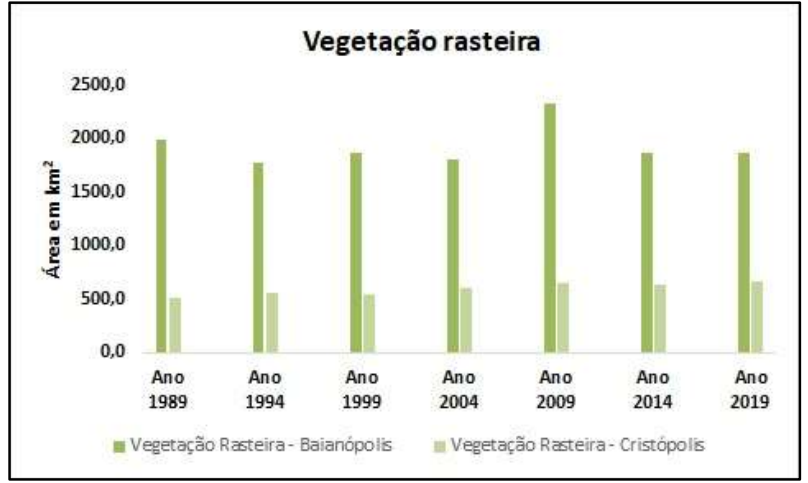

Gráfico 4: Baianópolis e Cristópolis na Bahia em 30 anos. Fonte: INPE (2019).

Esse tipo de vegetação é predominante no Cerrado e convive harmoniosamente com a vegetação arbustiva e lenhosa. Para Scholz et al. (2007), esse tipo de vegetação possui raízes superficiais e captam água

\footnotetext{
${ }^{2}$ Fronteira agrícola brasileira que compreende 337 municípios, em quatro estados, sendo Maranhão, Tocantins, Piauí e Bahia, com extensão de 73.848.967 hectares e abrange os biomas Cerrado (91\%), Amazônia (7,3\%) e Caatinga (1,7\%). Atualmente regido pelo Plano de Desenvolvimento Agropecuário - PDA - do decreto 8.447/2015.
} 
na parte superficial do solo para resistir ao período de seca.

Por meio de observações in loco, é possível afirmar que a vegetação rasteira presente nos territórios abordados neste trabalho não é exclusivamente nativa. Há uma substituição dessa mata por áreas de pastagens, agricultura e florestas plantadas, o que, para Klink et al. (2005), correspondem às formas de cobertura vegetal atualmente mais encontradas no Cerrado desmatado. Vale ressaltar aqui que essas atividades mencionadas ocorrem nas áreas dos municípios que compõem esta pesquisa.

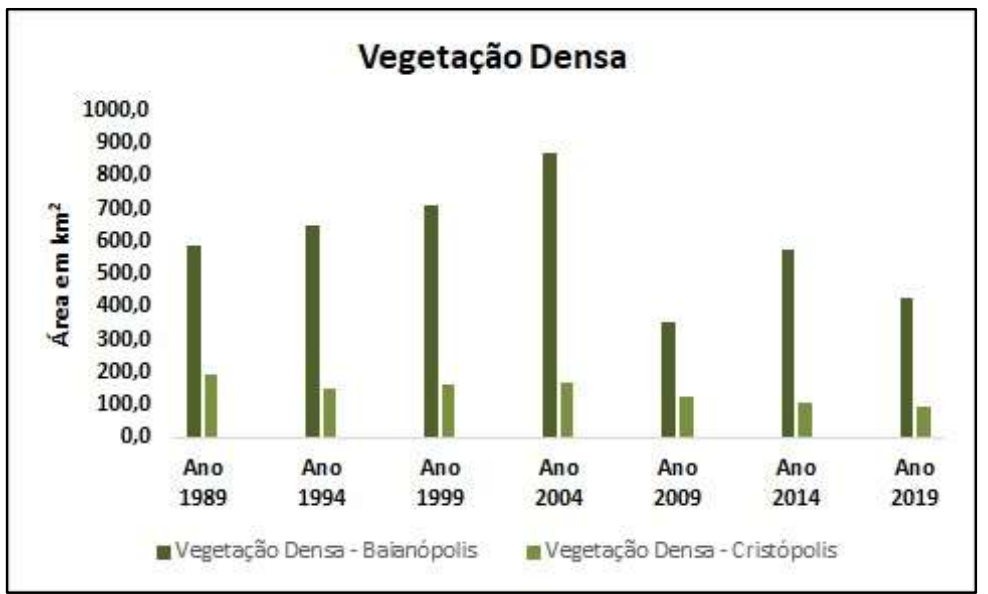

Gráfico 5: Baianópolis e Cristópolis na Bahia em 30 anos. Fonte: INPE (2019).

O Gráfico 5 mostra dados de uso e ocupação da vegetação densa nos municípios de Baianópolis e Cristópolis. Verifica-se que o ápice dessa cobertura foi no ano de 2004 para ambos os territórios, havendo perdas consideráveis dessa fitofisionomia após esse período.

Observou-se que houve a conversão de vegetação densa em área de plantio em ambos os municípios ao longo da primeira década do século XXI, o que condiz com os dados da pesquisa de Rocha et al. (2012), realizada para diagnosticar desmatamento no Cerrado, na qual foi observado que $90 \%$ dos desmatamentos ocorridos entre 2002 e 2009 no bioma tiveram concentrações em áreas de vegetação densa.

Esse período do século XXI marcou também o início da expansão agrícola no interior estado da Bahia, surgindo por exemplo o MATOPIBA (SILVA et al., 2018), o que pode ter colaborado com a diminuição desse tipo de vegetação. Essa também foi o diagnóstico de Rocha et al. (2012), ainda em relação ao desmatamento do Cerrado.

Atualmente, a fitofisionomia densa dos territórios de Baianópolis e Cristópolis, foi reduzida consideravelmente, principalmente quando comparada com 1989. Chama atenção, ainda, o fato de Cristópolis já ter perdido, em trinta anos, mais de 50\% dessa vegetação, correspondendo a uma perda média de $16,6 \%$ a cada década, enquanto em Baianópolis, houve um decréscimo de $27 \%$ no mesmo período, representando uma perda média de $9 \%$ em cada decênio.

\section{CONCLUSÕES}

Com base na intepretação das imagens de satélite e dados obtidos, verifica-se que houve significativas transformações espaço-temporais nas formas de uso e ocupação do solo do Cerrado nos municípios de Baianópolis e Cristópolis, se considerados os anos examinados. Ainda na escala dessas 
unidades político-administrativas, o Cerrado perdeu considerável área, o que contribui para a alta taxa de perda do bioma na sua totalidade.

A atividade de agricultura é a principal causa do desmatamento nessas áreas, uma vez que os municípios possuem atuação na produção de grãos e fazem parte da fronteira de extensão do agronegócio, necessitando, assim, cada vez mais de território plantável. Ainda que sejam apresentadas e implementadas tecnologias que visam a diminuição de áreas plantadas, as pesquisas apontam o forte crescimento das áreas de cultivo. Este sentido, a agricultura segue sendo a causa principal de destruição do Cerrado brasileiro. 0 crescimento econômico proporcionado pelo agronegócio está inversamente proporcional à degradação ambiental e seus impactos sociais para as populações local, regional, bem como à vida na Terra como um todo.

As queimadas são muito presentes nos municípios e constituem ferramenta aceleradora e facilitadora para preparação inicial do solo para plantio. Contudo, não se pode negar que há, também, ocorrência de incêndio involuntários. Porém, os dados visualizados neste trabalho denotam que, à medida que o fogo aumentou, a quantidade de área para a agricultura cresceu, deixando clara a relação entre essas classes.

Além disso, os territórios de Cristópolis e Baianópolis possuem perdas consideráveis de áreas nativas que foram transformadas em solos expostos. Esse é o resultado inicial de um desmatamento ou uma queimada, que geralmente são convertidos em agropecuária e quando não, necessitam de intervenção humana para que possam se recuperar e voltar a ser coberto pela vegetação nativa.

A fitofisionomia do Cerrado vai perdendo a sua identidade à medida que o desmatamento avança. A vegetação rasteira, apresentada nessa pesquisa se mostra crescente pelas imagens interpretadas, porém pela visita in loco, percebe-se que se trata apenas do crescimento da agricultura e de plantações de objetivo meramente econômico (maioria rasteiro, gramíneas e arbustivas), que se expandiram nessas regiões.

A vegetação densa foi reduzida pela metade no município de Cristópolis e em mais de um terço em Baianópolis, sendo parte dessa fitofisionomia transformada em agricultura, evidenciando que o desmatamento atinge todo tipo de vegetação no Cerrado e não está restrito apenas a um ou outro.

É cada vez mais necessária a mudança de atitude e criação de políticas voltadas para a questões ambientais onde técnicas de manejo sustentável sejam empregadas de forma obrigatória para que as perdas ambientais (biodiversidade, ecossistemas), sejam cessadas e para que os impactos sociais sejam minimizados. Essa deve ser a consciência política e social e pode ser empregada em todas os biomas da terra.

\section{REFERÊNCIAS}

ALCÂNTARA NETO, F.; LEITE, L. F. C.; ARNHOLD, E.; MACIEL; G. A.; CARNEIRO, F. V.. Compartimentos de carbono em Latossolo Vermelho sob cultivo de eucalipto e fitofisionomias de cerrado. Revista Brasileira de Ciência do Solo, v.35, p.849-856,2011. DOI:

https://doi.org/10.1590/S0100-06832011000300019

ALENCAR, A.; SHIMBO, J. Z.; LENTI, F.; MARQUES, C. B.; ZIMBRES, B.; ROSA, M.; ARRUDA, V.; CASTRO, I.; RIBEIRO, J.
P. F. M.; VARELA, V.; ALENCAR, I.; PIONTEKOWSKI, V.; RIBEIRO V.; BUSTAMANTE, M. M. C.; SANO, E. E.; BARROSO M.. Mapping Three Decades of Changes in the Brazilian Savanna Native Vegetation Using Landsat Data Processed in the Google Earth Engine Platform. Remote Sensing, v.12, n.924, 2020

ALVARADO, S. T.; FORNAZARI, T.; CÓSTOLA, A.; MORELLATO, L. P. C.; SILVA, F. S. F.. Drivers of fire occurrence in a 
mountainous Brazilian cerrado savanna: Tracking long-term fire regimes using remote sensing. Ecological Indicators, v.78, p.270-281, 2017. DOI:

https://doi.org/10.1016/j.ecolind.2017.02.037

ANACHE, J. A. A.; FLANAGAN, D. C.; SRIVASTAVA, A.; WENDLAND, E. C.. Land use and climate change impacts on runoff and soil erosion at the hillslope scale in the Brazilian Cerrado. Science of the Total Environment, v.622-623, p.140-151, 2018. DOI: https://doi.org/10.1016/i.scitotenv.2017.11.257

ARAÚJO, F. M.. Avaliação da área queimadas no bioma cerrado: proposições para o monitoramento e conversação. Tese (Doutorado em Ciências Ambientais) - Universidade Federal de Goiás, Goiânia, 2015.

BARBOSA, G. J.; COUTO, E. P.. Evolução das políticas agrícolas e o incentivo à iniciativa privada na agricultura brasileira. In: CONGRESSO DA SOCIEDADE BRASILEIRA DE ECONOMIA, ADMINISTRAÇÃO E SOCIOLOGIA RURAL. Anais. 2008. p.20.

BORGES, E. F.; SANO, E. E.. Séries temporais de EVI do Modis para o mapeamento de uso e cobertura vegetal do Oeste da Bahia. Boletim Ciências Geodésicas, Curitiba, v.20, no 3, p.526-547, 2014. DOI: https://doi.org/10.1590/S198221702014000200030

BUAINAIN, A. M.; GARCIA, J. R.. Crescimento da agricultura no cerrado nordestino: fatores condicionantes, limites e resultados socioeconômicos. 2016. In: AGRICULTURA, TRANSFORMAÇÃO PRODUTIVA E SUSTENTABILIDADE. Anais. 2016. p.391.

CBPM. Companhia Baiana de Pesquisa Mineral. Meio Ambiente na Bahia. Salvador: CBPM, 2007.

CHAICHI, N.; DAIM, T. U.. Landscape Analysis: Connected Lighting System. Infrastructure and Technology Management, v.1, p.45-65, 2018.

COCHRANE, M. A.. Tropical fire ecology: climate change, land use and ecosystem dynamics. Praxis Plublishing Ltd, 2009.

CORRÊA, R. S.; MELO, B. F.. Ecologia da revegetação em áreas escavadas. In: CORRÊA, R. S.; MELO, B. F.. Ecologia e recuperação de áreas degradadas no Cerrado. Brasília: Paralelo, 1998. p.65-99.

COUTINHO, M. L.. O Bioma Cerrado. In: Eugen warming e o Cerrado Brasileiro. São Paulo: Unesp, 2008. p.64-77.

EMBRAPA. Empresa Brasileira de Pesquisa Agropecuária. Com alho livre de vírus, a produção de Cristópolis/BA triplicou em dez anos. Embrapa Hortaliças, 2013.

FAUSTO, M. A.; ANGELINI, L. P.; MARQUES, H. O.; FILHO, A. S.; MACHADO, N. G.. Impacto da alteração do uso do solo no saldo de radiação no Cerrado do sul de Mato Grosso. Ambiente \& Água, v.11, n.2, p.350-361, 2016. DOI: https://doi.org/10.4136/ambi-agua.1843

FLORES, P. M.; GUIMARÃES, R. F.; CARVALHO JUNIOR, A. O.; GOMES, T. A. R.. Análise Multitemporal da Expansão Agrícola no Município de Barreiras - Bahia (1988 - 2008). Campo-
Território: Revista de geografia agrária, v.7, n.14, p.1-19, 2012.

GARCIA, A. L.. As exportações brasileiras entre 1998 e 2018. Universidade Federal de Uberlândia, 2019.

GOERL, R. F.; SIEFERT, C. A. C.; SCHULTZ, G. B.; SANTOS, C. S.. Development and application of landscape fragmentation and connectivity index to watershed analysis. Revista Brasileira de Geografia Física, Santos, v.5, p.1000-1012, 2011.

GOMIDE, P. H. O.; SILVA, M. L. N.; SOARES, C. R. F. S.. Atributos físicos, químicos e biológicos do solo em ambientes de voçorocas no município de Lavras/MG. Revista Brasileira Ciência do Solo, v.35, p.567-577, 2011. DOI: https://doi.org/10.1590/\$0100-06832011000200026

GONÇALVES, H.; MENEGUZZO, I. S.; MORO, R. S.. Políticas públicas para a conservação do Bioma Cerrado no Estado do Paraná, Brasil. Terr@ Plural, v.13, n.1, p.138-152, 2019. DOI: https://doi.org/10.5212/TerraPlural.v.13i1.0009

GONÇALVES, J. S.. Reprimarização ou desindustrialização da economia brasileira: uma leitura a partir das exportações para o período 1997-2010. Análise Indicadores Agronegócio, v.6, n.2, p.7, 2011.

GOUDIE, A. S.. Human impacto in the natural environment. 8 ed. University of Oxford, 2018.

GRANEMANN, D. C.; CARNEIRO, G. L.. Monitoramento de focos de incêndio e áreas queimadas com a utilização de imagens de sensoriamento remoto. Revista de Engenharia e Tecnologia, v.1, n.1, p.55-62, 2009.

GUIMARÃES, B. P.; GOMES, R. A. T.; CARVALHO JÚNIOR, O. A.; GUIMARÃES, R. F.; HERMUCHE, P. M.. Dinâmica do Uso e Cobertura da Terra no Município de Baianópolis (Ba) no Período de Vinte Anos (1988-2008). Revista Espaço e Geografia, v.20, n.3, 2018.

HELFAND, S. M.; REZENDE, G. C.. Região e espaço no desenvolvimento agrícola brasileiro. Repositório IPEA, 2003.

HUGHES, C. E.. Are there many different routes to becoming a global biodiversity hotspot?. Proceedings of the National Academy of Sciences, v.114, n.17, p.4275-4277, 2017. DOI: https://doi.org/10.1073/pnas.1703798114

INPE. Instituto Nacional de Pesquisas Espaciais. Queimadas. INPE, 2019.

IPEA. Instituto de Pesquisa Econômica Aplicada. Produção agrícola e área plantada por cidade do Brasil-Cristópolis, BA. IPEA, 2011.

JACON, A. D.; GALVÃO, L. S.; SANTOS, J. R.; SANO, E. E. Seasonal characterization and discrimination of savannah physiognomies in Brazil using hyperspectral metrics from Hyperion/EO-1. International Journal Remote Sensing, n.38, p.4494-4516, 2017. DOI: https://doi.org/10.1080/01431161.2017.1320443

JESUS, J. B.; NIEDERAUER, C. R.; ÍKARO, D. C. B.; MILTON, M. F.. Análise da incidência temporal, espacial e de tendência 
de fogo nos biomas e unidades de conservação do Brasil.

Ciência Florestal, v.30, n.1, p.176-191, 2020. DOI: https://doi.org/10.5902/1980509837696

KLINK, C. A.; MACHADO, R. B.. Conservation of the Brazilian Cerrado. Conservation Biology, v.19, p.707-713, 2005. DOI: https://doi.org/10.1111/j.1523-1739.2005.00702.x

LAPOLA, D. M.; MARTINELLI, L. A.; PERES, C. A.; OMETTO, J. P. H. B.; FERREIRA, M. E.; NOBRE, C. A.; AGUIAR, A. P. D.; BUSTAMANTE, M. M. C.; CARDOSO, M. F.; COSTA, M. H.; JOLY, C. A.; LEITE, C. C.; MOUTINHO, P.; SAMPAIO, G.; STRASSBURG, B. B. N.; VIEIRA, I. C. G.. Pervasive transition of the Brazilian land-use system. Nature Climate Change, n.4, p.27-35, 2014.

LEMES, G. P.; MATRICARDI, E. A. T.; COSTA, O. B.; LEAL, F. A. Avaliação espaço-temporal dos incêndios florestais no Parque Nacional Serra da Canastra no período de 1991 a 2011. Ambiência, v.10, n.1, p.247-266, 2014.

MDA. Sistema de informação Territorial. Bacia do Rio Grande/BA. Desenvolvimento Territorial. Caderno Territorial, 2011.

MENKE, A. B.; CARVALHO JUNIOR, O. A.; GOMES, R. A. T.; MARTINS, E. S.; OLIVEIRA, S. N.. Análise das mudanças do uso agrícola da terra a partir de dados de sensoriamento remoto multitemporal no município de Luís Eduardo Magalhães (BA - Brasil). Sociedade \& Natureza, v.21, n.3, p.315-326, 2009. DOI: https://doi.org/10.1590/S1982$\underline{45132009000300007}$

MESQUITA, F. W.; LIMA, N. R. G. L.; GONÇALVES, C. N.; BERLINCK, C. N.; LINTOMEN, B. S.. Histórico dos incêndios na vegetação do Parque Nacional da Chapada Diamantina, entre 1973 e abril de 2010, com base em imagens Landsat. Biodiversidade Brasileira, v.2, p.228-246, 2011.

MIRANDA, E. E.. Matopiba: caracterização, agendas e agência. Visual, 2015.

MMA. Ministério do Meio Ambiente. Plano de ação para prevenção e controle do desmatamento e das queimadas no Cerrado: PP Cerrado. Brasília: MMA, 2009.

OLIVEIRA, A. C. S.; MARTINS, G. N.; SILVA, R. F.; VIEIRA, H. D. Testes de vigor em sementes baseados no desempenho de plântulas. Inter Science Place, v.1, n.4, 2015.

RIDD, M. K.; LIU, J. A.. Comparison of Four Algorithms for Change Detection in an Urban Environment. Remote Sensing Environmental, v.63, n.1, p.95-100,1998.

ROCHA, G. F.; GUIMARÃES FERREIRA, L.; CLEMENTINO FERREIRA, N.; FERREIRA, E. M.. Detecção de Desmatamentos no Bioma Cerrado entre 2002 e 2009: Padrões, Tendências e Impactos. Revista Brasileira de Cartografia, v.63, n.3, 2012.

SANO, E. E.; SANTOS, C. C. M.; SILVA, E. M.; CHAVES, J. M.. Fronteira Agrícola do Oeste Baiano: Considerações Sobre os Aspectos Temporais e Ambientais. UNESP Geociências, v.30, n.3, p.479-489, 2011.

SANTOS, R. M.. Environmental Analysis and temporal and spatial patterns of land use changes in São Félix do Araguaia municipality (MT, Brazil). Thesis (Ph.D. in Natural Resources Ecology) - Federal University of São Carlos, São Carlos, 2011.

SCHOLZ, F. G.; BUCCI, S. J.; GOLDSTEIN, G.; MEINZER, F. C.; FRANCO, A. C.; MIRALLES-WILHELM, F.. Biophysical properties and functional significance of stem water storage tissues in neotropical savanna trees. Plant Cell Environment, v.30, p.236-248, 2007. DOI: https://doi.org/10.1111/j.13653040.2006.01623.x

SEAGRI. Secretaria de Agricultura do Estado da Bahia. Agronegócio na Bahia. Plantar, Colher e Alimentar Bons Resultados. Salvador: SEAGRI, 2017.

SEAGRI. Secretaria de Agricultura do Estado da Bahia. Apoio a produtores do Sudoeste e do Médio São Francisco teve o investimento dobrado. Salvador: SEAGRI, 2003.

SEl. Superintendência de Estudo Econômico e Social da Bahia. Perfil Socioeconômico do Município de Baianópolis. Salvador: SEI, 2011.

SILVA, M. M.. Frações de carbono do solo sob diferentes fitofisionomias do cerrado no Parque Nacional das Nascentes do Rio Parnaíba. Instituto Federal de Educação, Ciência e Tecnologia Goiano, 2019.

SILVA, S. D.; BOAVENTURA, J. K.; PORFÍRIO JÚNIOR, D. E.; MELO, N. C.. A última fronteira agrícola do Brasil: o Matopiba e os desafios de proteção ambiental no Cerrado. Estudios Rurales, v.8, p.145-178, 2018.

SIQUEIRA, M. N.. Influência do efeito de borda, da perda de habitat e de fatores abióticos na estrutura da comunidade lenhosa em fragmentos de cerrado denso na Alta Bacia do rio Araguaia. Tese (Doutorado em Ciências Ambientais) Universidade Federal de Goiás, Goiânia, 2016.

SOULSBURY, C. D.; WHITE, P. C. L.. Human-wildlife interactions in urban areas: a review of conflicts, benefits and opportunities. Wildlife Research, n.42, v.7, p.541-553, 2015. DOI: https://doi.org/10.1071/WR14229

SOUZA, G. V. A; SILVA L. R.. Agronegócio e Dependência: uma perspectiva de análise sobre a região do Matopiba. Caminhos de Geografia, v.20, n.72, p.149-168, 2019. DOI: https://doi.org/10.14393/RCG207242795

VACCHIANO, M. C.; SANTOS, J. W. C. M.; ANGEOLETTO, F.; SILVA, N. M.. Do data support claims that brazil leads the world in environmental preservation?. Environmental Conservation, v.46, n.2, p.118-120, 2019.

ZANIN, V.; BACHA, C. J. C.. A importância dos sojicultores sulistas na nova fronteira agrícola brasileira. Indicadores Econômicos FEE, v.45, n.1, p.35-52, 2017.

A CBPC - Companhia Brasileira de Produção Científica (CNPJ: 11.221.422/0001-03) detém os direitos materiais desta publicação. Os direitos referem-se à publicação do trabalho em qualquer parte do mundo, incluindo os direitos às renovações, expansões e disseminações da contribuição, bem como outros direitos subsidiários. Todos os trabalhos publicados eletronicamente poderão posteriormente ser publicados em coletâneas impressas sob coordenação da Sustenere Publishing, da Companhia Brasileira de Produção Científica e seus parceiros autorizados. Os (as) autores (as) preservam os direitos autorais, mas não têm permissão para a publicação da contribuição em outro meio, impresso ou digital, em português ou em tradução. 